\title{
Assessment of the influence of beach management units on fisheries governance in Migingo island, Kenya
}

\author{
Lucky Cinny Tubman $^{1}$, Kariuki Muigua ${ }^{2}$, Nzioka J. Muthama ${ }^{1}$ \\ ${ }^{1}$ Wangari Maathai Institute for Peace and Environmental Studies, University of Nairobi \\ ${ }^{2}$ School of Law, University of Nairobi
}

\begin{tabular}{|c|c|}
\hline & A BSTRACT \\
\hline $\begin{array}{l}\text { Article history: } \\
\text { Received: } 28 \text { October } 2020 \\
\text { Revised: } 16 \text { April } 2021 \\
\text { Accepted: } 22 \text { April } 2021 \\
\text { Available online: } 26 \text { August } 2021\end{array}$ & $\begin{array}{l}\text { Beach Management Units (BMUs) in Kenya were established to ensure sustainable utilization and } \\
\text { management of the fishery resource. BMUs as co-management institutions were conceptualized } \\
\text { after the failed state-controlled fisheries management. Sustainable management by the BMUs has } \\
\text { however not been realized, years after the institution's inception. The study aimed to assess the } \\
\text { management of Migingo BMUs; establish the effects of management of BMUs on the implementation } \\
\text { of the regulations; and assess the implementation of regulations with regards to fish stocks. The } \\
\text { study was done in Migingo Island, Lake Victoria which borders Kenya and Uganda. Data was } \\
\text { collected from the BMU committee members and stakeholders at the fish landing site along the } \\
\text { island's shores. This was done through a questionnaire based survey; semi structured interviews from }\end{array}$ \\
\hline $\begin{array}{l}\text { Corresponding Author: } \\
\text { Lucky Cinny Tubman } \\
\text { Email Address: } \\
\text { cinnylucky@gmail.com }\end{array}$ & $\begin{array}{l}\text { key informants and; focus discussion groups. Results revealed that the three out of seven functions } \\
\text { were performed satisfactorily by the Migingo BMU. These were revenue collection, confiscation of } \\
\text { illegal gears and arrest of offenders, as depicted by the satisfaction of respondents at } 42 \%, 38 \% \text {, } \\
\text { and } 68 \% \text {, respectively. The other functions - conducting meetings, patrol of the lake, formulation } \\
\text { of bylaws and inventory keeping had poor performance. Migingo's BMU structure was found to be } \\
\text { wanting as it lacked the assembly branch. Implementation of regulations by the BMU faced various } \\
\text { challenges; lack of support from the government, inadequate funds and equipment and inadequate } \\
\text { knowledge to operate its functions. This study shows that BMUs are viable institutions however the }\end{array}$ \\
\hline $\begin{array}{l}\text { Key words: } \\
\text { Fisheries, } \\
\text { Co-management, } \\
\text { Beach Management Units, } \\
\text { Governance }\end{array}$ & $\begin{array}{l}\text { poor structure and management of Migingo's BMU along with the challenges faced in implementing } \\
\text { the stipulated regulations led to its ineffectiveness. Capacity building is therefore needed on the } \\
\text { BMU's management and governance at large, provision of relevant skills, equipment and funds and } \\
\text { improved support from the government for the BMU to be efficient and effective. }\end{array}$ \\
\hline
\end{tabular}

\section{Introduction}

Fisheries play an important role in the socio economic development of Kenya and has over the years contributed to the gross domestic product (GDP), from 5\% in 2004 to $0.54 \%$ in 2013 albeit in a decreasing trend (Muigua et al., 2015 and FAO, 2016). This is evident as it supports various livelihoods, offers employment avenues and generates income. The resource is also essential as it ensures the food security of the nation is attained. Fisheries resource refers to components of a natural aquatic resource for example species, populations, stocks and assemblages which can be legally caught by fishing (FAO, 2016).
Fisheries all over the world are in crisis due to several factors. According to (Abila et al., 2000) these factors can be categorized into three domains. The first is economic: intensification of fishing capital and labor caused by redundant catching capacity, declining incomes and high cost. The second is biological- the threat of fish stock depletion. The third being governance which comes along because of fisheries management that is excessively centralized. This worrying trend of fish stock devastation is quite evident in Kenya. It is particularly visible in L. Victoria's fishery, the nation's principal fishery producer having surpassed the marine production (Japp, 2012).

The management of Lake Victoria's resources began in 
the 18 th century under the traditional regime. Fishing activities were informal, rooted in the community's culture and was exclusively for the riparian communities. In this administration, fishers participated in the decision making of the fisheries management. It was during the colonial times that formal management of the resource commenced, with the enactment of the Fish Ordinance (Luomba and Kristofersson, 2013). This mode of management was continued after independence as the central government exercised full authority over the resource. Under this state-controlled management, there was minimum to no room for the stakeholders' involvement in the decision-making process. Lawrence \& Watkins (2011) state that this system of management could not sustain the fisheries that people depended on for their livelihoods. This necessitated a change in the management system due to the declining fish catches and the deteriorating state of the lake ecosystem. It led to a shift, a collaborative management approach which at all levels involved the stakeholders from that of a centralized one ( Njiru et al., 2008).

The ineffectiveness of the state's command and control administration led to the widespread adoption of the fisheries co-management approach (Nunan, 2010). Co management is a system where there is a shared responsibility and authority over the management of a common resource between; resource users, the government and other stakeholders to administer the resource jointly (Abila et al., 2009). The opinions of the fisher folk are incorporated during the decision making process and the execution of management measures. This enhances the legitimacy of the decided regulations resulting to more inclination of the fishers to follow them (Ogwang, 2005).

The fishing community around L. Victoria participate in co management of the resource through Beach Management Units (BMUs). According to Abila (2014) Beach Management Unit is an organization within the fishing community at the beach of fisher folk. This includes the fishermen, vessel owners, managers, fish processors, fish mongers, gear makers or repairers and fishing equipment dealers. This institution as recognized in the Fisheries Management and Development Act 2016, allows for co-management of the local fisheries by the community and the government.

BMUs are key institutions in ensuring sustainable use and conservation of aquatic resources as their regulations deters use of illegal gears, observance of closed seasons and areas, and limitation in the number of fishing vessels on the lake. These measures supports the replenishment of fish stocks hence avoiding its devastation, deters overexploitation and ensures the resource reaches maturity for reproduction purposes. Data collection and records keeping, as a major function of the BMU also contributes to the resource's sustainability as it keeps account of the quantity, quality and fish species. Detection of change in the fish stock abundance is therefore easily noticed hence measures can be taken to control the situation.
Although co management over the fisheries has been adopted, there is continuous pressure in terms of catch and effort on the resource (van der Knaap et al., 2002). This has led to the decline of fish stock in the lake hence largely affecting the community's livelihood. The dwindling fish stocks have also steered conflicts over rich fishing grounds as was the case with Kenya and Uganda's row over Migingo Island a few years ago. Concerns have therefore been raised about the co management's ability to sustainably manage the resource. It is evident that a gap is existent between the set regulations of the BMUs (co management) and its implementation which largely lies in the management and governance docket. Hence the purpose of this study is to assess co management, BMUs, on the governance of the fisheries resource. It specifically aimed to; assess the management of BMUs (in terms of structure and functions); establish the effects of management of BMUs on the implementation of the regulations; and assess the implementation of regulations with regards to fish stocks.

\section{Hypothesis}

1. $\mathrm{H}_{0}$; Community participation does not influence the efficient management of BMUs.

$\mathrm{H}_{1}$; Community participation influences the efficient management of BMUs.

2. $\mathrm{H}_{0}$; Efficient management of BMUs does not lead to the implementation of regulations.

$\mathrm{H}_{1}$; Efficient management of BMUs leads to the implementation of regulations.

3. $\mathrm{H}_{0}$; Implementation of regulations by the BMUs has no effect on the fish stocks.

$\mathrm{H}_{1}$; Implementation of regulations by the BMUs has an effect on the fish stocks.

\section{Materials and Methods}

\subsection{Study area}

Migingo Island covers a total surface area of 0.49 acres. The Island is located east of the border of Kenya and Uganda, approximately 510 meters away within the lake. The land in Migingo is rocky, rugged and with little vegetation (Fig. 1). According to the Kenyan census in 2009, the population of the island was said to be 131 people.

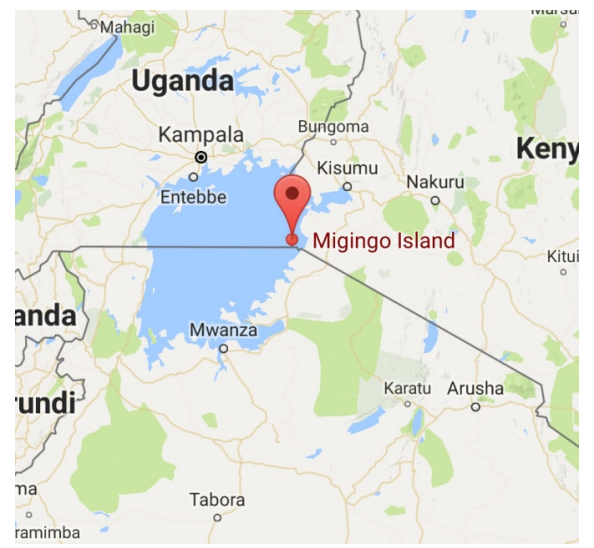

Fig. 1. Map of Lake Victoria, Migingo Island Adapted from Wikipedia 
The research studied the Migingo Beach Management Unit as it was the only existing one at the time and catered for the entire island. This can largely be attributed to the small geographical area the island covers. The survey made use of a two stratified random sampling technique in order to achieve its purpose and obtain a representative sample. For the first strata, participants were chosen based on their membership in the Migingo BMU. They were selected to gain a deeper insight on management related activities and the variables that may have an impact on these activities. The findings revealed the poor registration of members in the BMU since they had fifteen members who were chosen to be respondents. For the second strata the participant were selected based on their occupation, direct stakeholders in the fishery resource. These were boat owners, fishermen, traders and service providers. The number from the first strata was predetermined as it was only limited to the members. From the second strata the respondents were selected randomly ending up with 35 respondents, coming up with a total of 50 respondents.

\subsection{Data Collection}

Primary data was obtained through questionnaires, semi structured interviews, focus discussion groups and observations. Questionnaires were administered to the stakeholders in the fisheries sector- boat owners, fisher folk, traders and service providers. The responses gave an insight into the respondent's feelings, background, attitudes and knowledge. Key informants such as; the BMU chairperson, representatives from the county government and fisheries department were selected for the semi structured interviews.

Secondary data was acquired from extensive literature review through the internet, review of journals, books, articles, Constitution of Kenya 2010 and the Fisheries (Beach Management Units) Regulations Act 2007. These provided essential additional details to the study.

\subsection{Data Analysis}

Once data was collected, it was coded and entered in a computer worksheet- Statistical Package for Social Sciences (SPSS) version 20.0 and Microsoft Excel for further analysis. Afterwards, descriptive statistics such as frequency counts, chi square $\left(\mathrm{x}^{2}\right)$ goodness of fit, cross- tabulations and percentage distribution techniques were used to analyze this data. The results were presented using frequency distribution tables, pie charts and bar graphs. Qualitative data was analysed using content based on meanings and implications emanating from respondents' information and documented data.

\section{Results and Discussions}

\subsection{Demographic characteristics}

\subsubsection{Nationality}

The respondents under the study were 68\% Kenyans while $18 \%$ were Ugandans and $14 \%$ Tanzanians as observed in Fig. 2. The composition of the respondent's nationalities can be attributed to the trans boundary location of the Island as well as the rich fishing grounds around it that attracts people from the three countries.

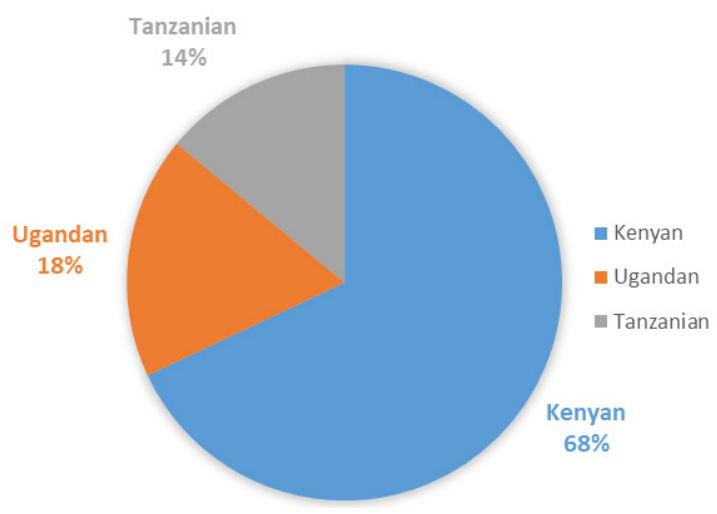

Fig. 2. Pie Chart of Respondents' Nationalities

Most of the respondents were Kenyans due to the close proximity of Migingo Island to the Kenyan coast as compared to the other two countries. The BMU system of fisheries co management has been adopted in the three member states of the East African Community hence the respondents demonstrated familiarity with the institution.

\subsubsection{Gender}

The male represented $72 \%$ of the respondents in the study while $28 \%$ were female (Fig. 3). This is due to the division of roles in fishing activities within the region according to gender (Lwenya et al., 2018). Majority of the fishermen and boat owners were male while traders and fish processors were mostly female.

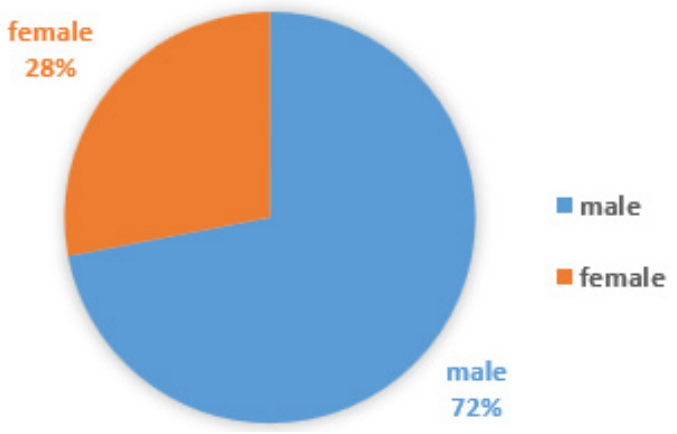

Fig. 3. Pie chart of Respondents' gender

\subsubsection{Position in Beach Management Units and occupation}

The BMU members formed $30 \%$ of the respondents while $70 \%$ were non-members of the BMU but were direct stakeholders in the fishing domain; fishermen, boat owners and service providers (Table 1 ). 
Table 1: Cross tabulation of the position in the BMUs and occupation of respondents

\begin{tabular}{lccccc}
\hline & & \multicolumn{3}{c}{ Occupation } & \multirow{2}{*}{ Total } \\
\cline { 2 - 5 } & Boat owner & Fisherman & Service providers & Traders & \\
\hline Member & $18 \%$ & $2 \%$ & $4 \%$ & $6 \%$ & $30 \%$ \\
Non-member & $6 \%$ & $32 \%$ & $14 \%$ & $18 \%$ & $70 \%$ \\
\hline Total & $24 \%$ & $34 \%$ & $18 \%$ & $24 \%$ & $100 \%$ \\
\hline
\end{tabular}

The representation of fishermen in the BMU committee was poor while that of boat owners was high. From the table above it can be observed that the occupation of an individual had a great impact on their chances of being a BMU member. Boat owners have a higher chance of being members than traders, service providers and fishers. This implies that they generally have a strong influence on the decision making process of the fisheries management in the Island.

\subsection{Management of Beach Management Units}

\subsubsection{Structure of Beach Management Units}

Ideally a BMU should consist of a committee and an assembly in order to effectively perform its functions. According to (Ogwang, 2005) BMU should consist of an assembly and committee. The assembly membership should be of crew members, boat owners, fish processors and traders, boat makers, fish gear dealers \repairs and other fisheries related institutions operating at a particular beach. The BMU committee on the other hand should have a maximum of 15 members and they should represent boat owners, crew (fish laborers), stakeholders and fish traders. The study revealed that the Migingo BMU consists of a committee but lacked an assembly.

The absence of an assembly sets a weak foundation for the co management institution to efficiently run its operations. It brings about the validity of the existent BMU formation since the assembly selects members for the committee position. It also implies that the committee is not kept in check in terms of carrying out its roles and obligation to follow the set regulations.

\subsubsection{Representation}

From Table 2 various stakeholders are represented in the BMU committee. This enables exchange of ideas and adaptation of the best practices in managing and governing the fisheries resource. Muigua (2016) states that allowing and encouraging views from different groups to affect the outcome may increase the compliance, deter violations, and contribute to a more realistic and responsive management of natural resources.

Table 2: Table of respondents' view on the representation in the BMU committee

\begin{tabular}{lcccc}
\hline & Low & Moderate & High & Total \\
\hline Group & $\mathbf{9 2} \%$ & $\mathbf{8 \%}$ & $\mathbf{0 \%}$ & $\mathbf{1 0 0 \%}$ \\
\hline Member & $4 \%$ & $22 \%$ & $74 \%$ & $100 \%$ \\
Non-member & $42 \%$ & $50 \%$ & $8 \%$ & $100 \%$ \\
\hline Total & $70 \%$ & $18 \%$ & $12 \%$ & $100 \%$ \\
\hline
\end{tabular}

As indicated in Table 2 women representation in Migingo BMU was low as men are dominant. According to (Lwenya et al., 2018) the division of labor in Kenya's fishing community is clear cut and it is culturally defined. Traditionally men have been known to spend more time in fishing than women. This can be attributed to the labor intensive nature of fish harvesting usually taken up by men and women's role of taking care of the family that requires them to attend to household matters. As a result of this division, women have been marginalized in the decision making process of the management of the fishery resource hence few are rep- resented in the BMU committee. Boat owners on the other hand are reported to have a higher number in the committee.

According to (Nunan, 2010) when it comes to fishingrelated decisions, boat owners are main decision makers. They invest in the fishing industry, consider input needs such as boat repairs and cost of nets, oversee the sale of fish and payment of crew as well as monitor the catches. Their high representation in the committee can be credited to the mentioned critical role they play. This implies that they can sway the decision making process to their advantage at the 
expense of other groups. There is therefore a reduction in the diversity of solutions and alternatives in managing the BMU as the boat owners may intimidate and even frustrate efforts from the groups with fewer representation- fishermen and traders.

The poor representation of fishermen and women in the BMU committee showcased inadequate levels of equity and inclusiveness, an important principle of fisheries governance. Economic and social disparities caused by lack of access and poor representation in decision-making processes are likely to adversely affect the viability and growth of the rural economy (Ngwenya and Mosepele, 2012). As per the set BMU regulations, there should be adequate representation so as to achieve a wholesome approach for better governance of the resource economy growth and improved livelihoods.

\subsection{Functions of Beach Management Units}

\subsubsection{Conducting meetings}

From the study, most of the respondents were not satisfied with the BMUs performance of conducting meetings. The table above indicates that $18 \%$ and $26 \%$ of the respondents were highly unsatisfied and unsatisfied respectively. $24 \%$ had a neutral stand while $28 \%$ were satisfied and $4 \%$ were highly satisfied (Fig. 4).

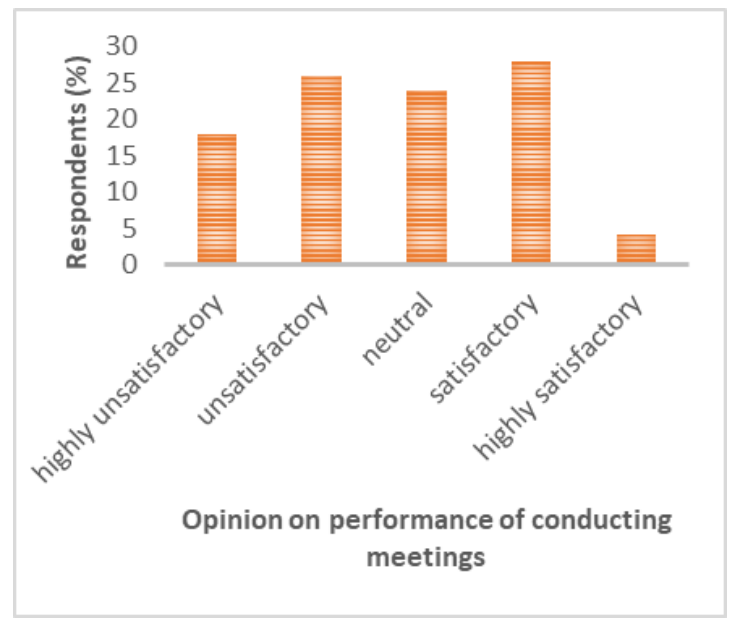

Fig. 4. BMUs performance on conducting meetings

According to (Ogwang, 2005) the harmonized BMU guidelines state that the BMU assembly should have meetings once every three months while the BMU committee should meet once every month, both meetings should be convened by the chairperson. Conducting meeting has been used as an indicator of BMU performance (Luomba, and Kristofersson, 2013) because this is an avenue for promoting dialogue between representative stakeholders' hence enhancing participation and transparency. This platform makes room for discussion on the effectiveness of the present management plan, strategies to be amended or introduced and formation of bylaws that seeks to enhance sustainable fisheries and improvement of livelihoods.

\subsubsection{Patrols of fishing grounds}

Patrols of the fishing ground have been put in place to reduce the incidences of illegal unregulated and unreported fishing activities. BMUs are therefore tasked with patrolling fishing grounds in order to facilitate sustainable fishing activities. Respondents from the study revealed that they were unsatisfied with the patrol activities, 30\% unsatisfied while $28 \%$ highly unsatisfied. $24 \%$ took a neutral position while $12 \%$ were satisfied and $6 \%$ highly satisfied with the patrols efforts put in place by BMUs as observed in Fig. 5. From the semi structured interviews, these findings corresponded with the absence of a patrol boat that the national and county government failed to purchase.

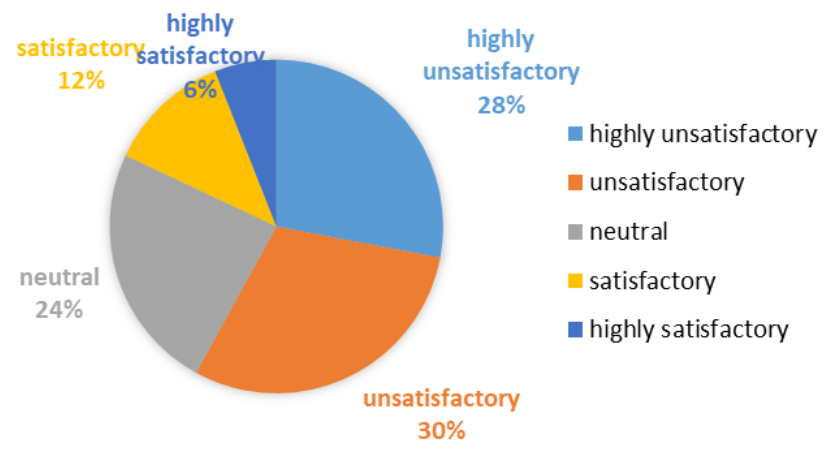

Fig. 5. BMUs performance on patrolling fishing grounds

From the semi structured interviews, these findings corresponded with the absence of a patrol boat that the national and county government failed to purchase. Lack of a patrol boat hinders this essential service hence makes room for non-compliance among the stakeholders particularly fishermen.

\subsubsection{Collecting revenue}

Most of the respondents were content with this activity, $26 \%$ were satisfied and $18 \%$ were highly satisfied. Quite a number, $36 \%$ were not sure of the performance. Few respondents $6 \%$ stated that they were highly unsatisfied and $14 \%$ unsatisfied with the efforts put in place to collect revenue as shown in Fig. 6. The chairman of the BMU stated that they imposed a $20 \%$ commission on the total quantity of fish landed in the Island per boat/vessel.

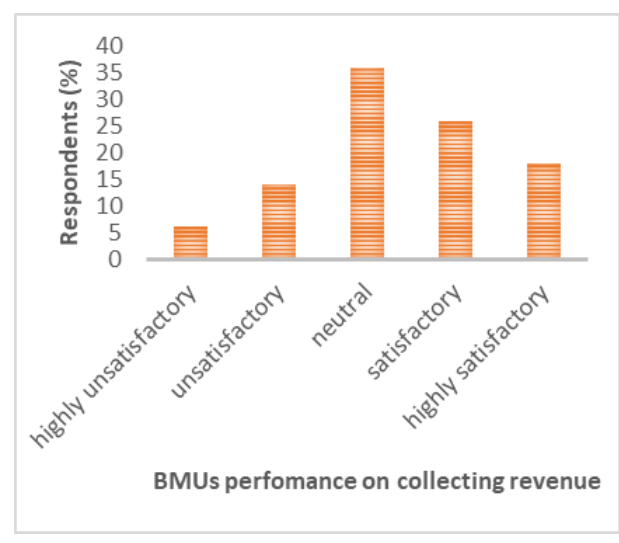

Fig. 6: BMUs performance on collecting revenue 
Collection of revenue is a source of income that enables the BMU to undertake its roles and operations effectively. This has however not been the case as there is little or no development in the infrastructure that aids the BMU operations. This issue of accountability and transparency is therefore raised in the management of BMU that directly impacts the fisheries governance.

\subsubsection{Formulation of by laws}

Bylaws are rules that govern a specific BMU and are in harmony with the BMU regional guidelines. However they need to be compatible with the general regulations and approved by the Director of Fisheries. Most of the respondents (Fig. 7) indicated that they were highly unsatisfied $20 \%$ and unsatisfied $28 \%$ with the formulation of bylaws. $24 \%$ took a neutral stand while $28 \%$ were satisfied (4\% highly satisfied and $24 \%$ satisfied). The unsatisfactory state of most of the respondents on the above mentioned function could be attributed to its non-participative nature, only committee members are involved in the formulation.

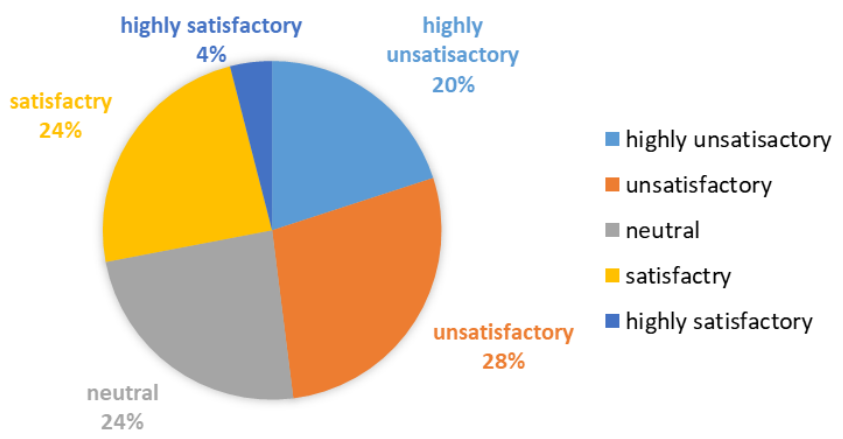

Fig. 7. BMUs performance on Formulating by Laws
BMUs are expected to engage with community members in their activities and make use of their opinions and indigenous knowledge to come up with bylaws best suited for the local environment, needs and demands so as to foster sustainable fishing. Engagement with the community also enables the BMUs to provide information with scientific backings that were previously unknown to the members. Formulation of bylaws therefore provides an avenue for scientific findings marrying with indigenous knowledge for effective management of BMUs. Lack of community participation as reported from the survey fails to explore this potential losing out on the transformation that could unfold. This non-participative nature also reveals the lack of equity and inclusiveness in the management of the BMU, negatively imposing on the fisheries governance.

From Table 3 majority of respondents indicated that meetings were conducted on a random basis. On the other hand most of the respondents were not satisfied with the level of formulating by laws by the BMU. The relationship between these two factors indicates that the absence of regular meetings makes it difficult for the BMU members to discuss developing issues and eventually formulate bylaws that addresses them.

Pomeroy et al., (2011) argues that co management should be viewed as a process of resource management, not as a single strategy to solve all problems of fisheries management, that matures, adjust and adapt to changing conditions over time. As such conducting meetings and formulating by laws on a regular basis enables the review of strategies that matures over time to adjust to changing conditions in order to be effective and efficient in the long run.

Table 3: Cross Tabulation of Frequency of Meetings and Formation of by Laws

\begin{tabular}{|c|c|c|c|c|c|c|c|}
\hline & & \multicolumn{5}{|c|}{ Formulation of by-laws } & \multirow{2}{*}{ Total } \\
\hline & & $\begin{array}{c}\text { highly } \\
\text { unsatisfactory }\end{array}$ & unsatisfactory & neutral & satisfactory & $\begin{array}{l}\text { highly sat- } \\
\text { isfactory }\end{array}$ & \\
\hline \multirow{3}{*}{$\begin{array}{l}\text { Frequency of } \\
\text { conducting } \\
\text { meetings }\end{array}$} & Member & $0 \%$ & $2 \%$ & $0 \%$ & $0 \%$ & $0 \%$ & $2 \%$ \\
\hline & Non-member & $2 \%$ & $0 \%$ & $2 \%$ & $10 \%$ & $0 \%$ & $14 \%$ \\
\hline & Randomly done & $18 \%$ & $26 \%$ & $22 \%$ & $14 \%$ & $4 \%$ & $84 \%$ \\
\hline \multicolumn{2}{|c|}{ Total } & $20 \%$ & $28 \%$ & $24 \%$ & $24 \%$ & $4 \%$ & $100 \%$ \\
\hline
\end{tabular}

\subsubsection{Inventories}

Most of the respondents were unsatisfied with the BMUs performance on keeping inventories- $12 \%$ highly unsatisfied and $26 \%$ unsatisfied. $40 \%$ took a neutral stand while $8 \%$ were highly satisfied and $14 \%$ satisfied as seen in Fig. 8. Records of inventories taken over the past months by the BMU were not as comprehensive as they ought to be, as such the information on the numbers of fishers and vessels as well as the quantity (kg or tonnes) and quality (maturity, age and species) of fish harvested was scanty. Assessment

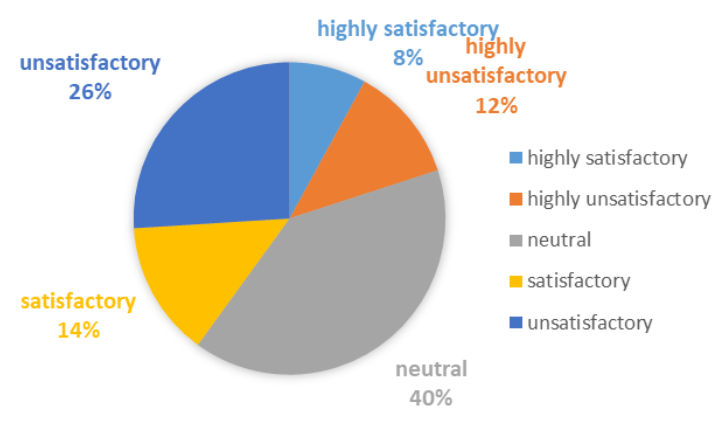

Fig. 8. BMUs performance on keeping inventories 
of the resource would therefore prove to be difficult due to lack of substantial information posing a hindrance to future monitoring, evaluation and planning. Inadequate inventory records hinders transparency to stakeholders making it difficult for them to hold the BMU accountable for its actions thus having a negative impact on fisheries governance.

\subsubsection{Confiscating illegal gears}

BMUs confiscate illegal gears to ensure immature fish are not captured hence enabling the regeneration of the resource. Fig. 9 revealed that $38 \%$ were satisfied with the efforts put in place to ensure that illegal gears were confiscated. A large number, 36\% of respondents took a neutral stand while $26 \%$ were unsatisfied with the interventions of confiscating illegal gears.

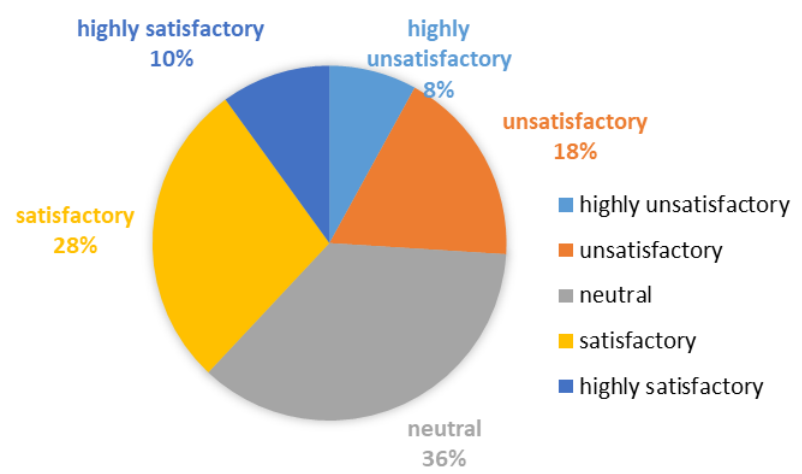

Fig. 9. BMUs performance on confiscating illegal gears

Upon confiscation of illegal gears, a hefty fine is imposed on the fisher as a form of punishment and a deterrent for other fishers not to engage in the same.

\subsection{Implementation of Regulations}

\subsubsection{Compliance}

Majority of the respondents $68 \%$ stated that the level of compliance to the regulations was moderate while compliance at both extremes were equal 16\% low and 16\% high. The table indicates that patrols of fishing grounds was randomly or never done. It also reveals that the frequency of patrols resulted to laxity among fishers leading to moderate compliance of regulations (Table 4).

Table 4. Cross tabulation on compliance to regulations and frequency of patrols made

\begin{tabular}{llcccc}
\hline & & \multicolumn{3}{c}{ Level of compliance } & \\
\cline { 3 - 5 } & & High & Low & Medium & Total \\
\hline \multirow{3}{*}{$\begin{array}{l}\text { Frequency } \\
\text { of patrols }\end{array}$} & Daily & $2 \%$ & $2 \%$ & $16 \%$ & $20 \%$ \\
made & Nonthly & $0 \%$ & $0 \%$ & $2 \%$ & $2 \%$ \\
& Randomly done & $8 \%$ & $12 \%$ & $18 \%$ & $38 \%$ \\
\hline & Total & $16 \%$ & $16 \%$ & $68 \%$ & $100 \%$ \\
\hline
\end{tabular}

Ideally the level of compliance to regulations would be higher if the BMU patrolled the fishing grounds more often. This would result to reduced cases of illegal, unregulated and unreported fishing activities hence safeguarding the sustainability of the resource as well as the community's livelihood.

\subsubsection{Constraints}

According to the respondents, $48 \%$ stated that lack of support from the national and county government was a constraint in the management of BMU. Figure 3.9 reveals that inadequate capacity and inadequate knowledge were constraints in implementing regulations, each with $24 \%$. Only $4 \%$ of the respondents stated that corruption was a challenge.

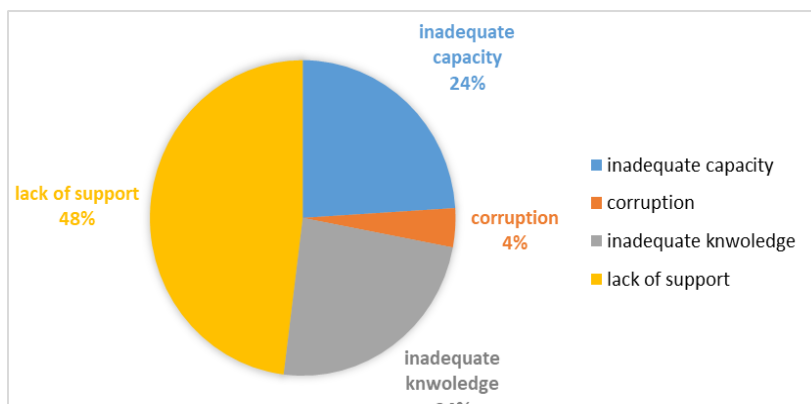

Fig. 10. Constraints to the implementation of regulations

Findings from Table 5 reveals the funds were deemed to be inadequate by the most of the respondents under the study as $50 \%$ of the respondents attested to it. $42 \%$ of the respondents however stated that the funds were not available. Inadequate funds by BMU could be attributed to lack of support from the government as well as corruption since funds collected through revenue were not channelled back in to the development of the BMU.

Table 5. Table on the adequacy of resources

\begin{tabular}{llcccc}
\hline Resources & $\begin{array}{l}\text { More than } \\
\text { adequate }\end{array}$ & $\begin{array}{c}\text { Ade- } \\
\text { quate }\end{array}$ & $\begin{array}{c}\text { Inade- } \\
\text { quate }\end{array}$ & $\begin{array}{c}\text { Not } \\
\text { available }\end{array}$ & Total \\
\hline Funds & $2 \%$ & $6 \%$ & $50 \%$ & $42 \%$ & $100 \%$ \\
Equipment & $4 \%$ & $0 \%$ & $38 \%$ & $58 \%$ & $100 \%$ \\
Manpower & $16 \%$ & $64 \%$ & $8 \%$ & $12 \%$ & $100 \%$ \\
\hline Legal power & $44 \%$ & $30 \%$ & $12 \%$ & $14 \%$ & $100 \%$ \\
\hline
\end{tabular}

Equipment that are essential in the management of the BMU were not available as reported by $58 \%$ of the respondents. Additionally $38 \%$ of the respondents said that they were inadequate. Most of the respondents indicated that manpower was adequate as the island attracts citizens from Kenya, Uganda and Tanzania. Legal power was also considered to be adequate by the respondents as a resource for the BMU to perform their duties. This could be attributed to the fact that BMUs are recognized under all the three countries and the presence of regional and national institutions as well as the fisheries regulations. 
These resources are crucial for the management of Migingo BMU as they provide the needed means to implement the regulations. Lack or inadequacy of the resource as witnessed hinders the effectiveness of the BMU operations for example patrol of fishing grounds is difficult as they don't have the required equipment- patrol boat and night goggles.

\subsection{Community participation}

\subsubsection{Access of Information}

Information should be made widely available by the state to encourage public awareness and participation (Muigua, 2016). From the study that was conducted, $64 \%$ of the respondents accessed information pertaining to the management of BMUs through word of mouth as shown in Fig. 11.

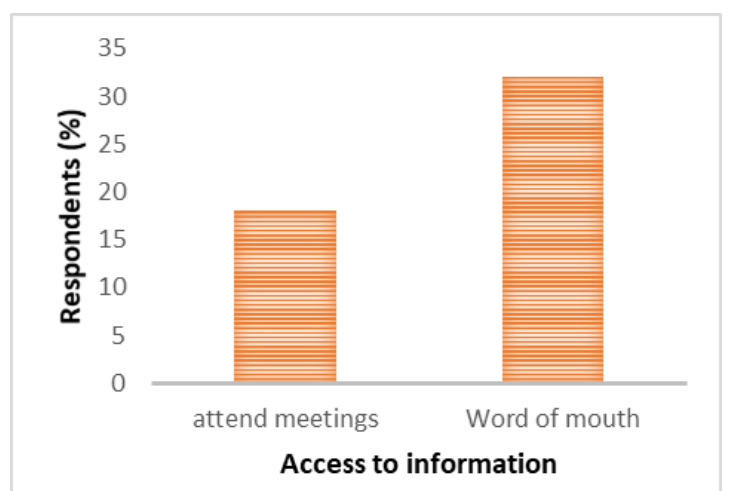

Fig. 11: Respondents access to information concerning BMUs

This kind of communication leads to distortion of information therefore unable to achieve its intended purpose. The remaining 36\% indicated that they attended meetings hence acquired the information. This occurrence could be attributed to the fact that BMU committee members are the only respondents who attended meetings.

The transparency principle dictates that information on fisheries management should be freely available and accessible to the stakeholders who will be directly affected by its implementation or lack of it thereof. Moreover the information should be in an easily understandable form and provided through relevant media that can reach the stakeholders. It also provides that decisions made and their enforcement should be in compliance with the set regulations and rules. The aspect of transparency in the Migingo BMU operations unfolds in the accessibility of information. The level of transparency within the institution is wanting due to the accessibility of information present to stakeholders making it difficult to hold the BMU accountable for its actions and procedures taken.

\subsubsection{Interest of the Community}

Direct user involvement in negotiations is believed to increase the legitimacy of rules and leads to better compliance (Muigua, 2015). The figure above shows that majority of the respondents $60 \%$, stated that the community's interest were not being represented by the BMU. The rest, $40 \%$ had the alternative opinion as observed in Fig. 12 Most of Migingo's occupants felt excluded by the BMU as their opinions were rarely sought after and they could hardly access information on BMUs operations.

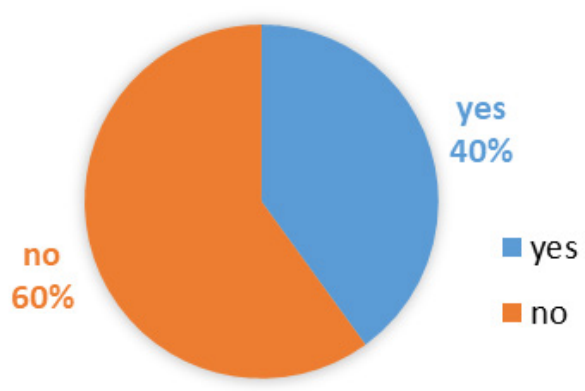

Fig. 12: Community's interest represented in management of BMUs

\subsection{Testing of Hypotheses}

\subsubsection{Hypothesis 1}

$\mathrm{H}_{0}$; Community participation does not influence the efficient management of BMUs.

$\mathrm{H}_{1}$; Community participation influences the efficient management of BMUs.

Table 6. Cross tabulation of the manpower resource and confiscation of illegal gears

\begin{tabular}{llcc}
\hline Manpower & \multicolumn{4}{l}{ Confiscation of illegal gears } \\
\hline & Monthly & Randomly & Total \\
\hline Adequate & 19 & 21 & 40 \\
Inadequate & 5 & 5 & 10 \\
\hline Total & 24 & 26 & 50 \\
\hline
\end{tabular}

Chi-square $X^{2}=\operatorname{Sum}(\mathrm{O}-\mathrm{E})=0.887448$

Number of degrees of freedom $\mathrm{df}=(\mathrm{r}-1)(\mathrm{c}-1)=1 \mathrm{x} 1=1$

Critical value at 1 degrees of freedom, whose P value is 0.05 was 6.314

The calculated value is less than the critical value hence we reject the null hypothesis and accept the alternative (Table 6). Therefore, community participation influences management of the BMU as they provide the needed manpower to ensure critical roles are carried out.

\subsubsection{Hypothesis 2}

$\mathrm{H}_{0}$; Efficient management of BMUs does not lead to the implementation of regulations.

$\mathrm{H}_{1}$; Efficient management of BMUs leads to the implementation of regulations. 
Table 7. Cross tabulation of the arrest offenders and compliance to regulations

\begin{tabular}{lccccc}
\hline & & \multicolumn{3}{c}{ Compliance } & Total \\
\cline { 3 - 5 } & & High & Low & Medium \\
\hline \multirow{2}{*}{$\begin{array}{l}\text { Arrest } \\
\text { offenders }\end{array}$} & Satisfactory & 6 & 7 & 19 & 31 \\
\hline Total & Unsatisfactory & 6 & 5 & 8 & 19 \\
\hline
\end{tabular}

Chi-square $X^{2}=\operatorname{sum}(\mathrm{O}-\mathrm{E})=0.341377$

Number of degrees of freedom $\mathrm{df}=(\mathrm{r}-1)(\mathrm{c}-1)=1 \mathrm{x} 2=2$

Critical value at 2 degrees of freedom whose $\mathrm{P}$ value is 0.05 was 2.920

The calculated value is less than the critical value hence we reject the null hypothesis and accept the alternative (Table 7). Therefore, efficient management of BMU leads to the implementation of regulations for instance arresting offenders instills fear on the fishers hence they comply with the regulations put in place.

\subsubsection{Hypothesis 3}

$\mathrm{H}_{0}$; Implementation of regulations has no effect on the fish stocks.

$\mathrm{H}_{1}$; Implementation of regulations has an effect on the fish stocks.

Table 8. Cross tabulation of the arrest offenders and compliance to regulations

\begin{tabular}{llcccc} 
& & \multicolumn{3}{c}{ Compliance } & Total \\
\cline { 3 - 5 } & & High & Low & Medium & \\
\hline \multirow{3}{*}{ Fish stock } & Increasing & 6 & 5 & 8 & 19 \\
& Decreasing & 7 & 9 & 15 & 31 \\
\hline \multirow{2}{*}{ Total } & & 13 & 14 & 23 & 50 \\
\hline
\end{tabular}

Chi-square $X^{2}=\operatorname{sum}(\mathrm{O}-\mathrm{E})=0.885848$

Number of degrees of freedom $\mathrm{df}=(\mathrm{r}-1)(\mathrm{c}-1)=1 \mathrm{x} 2=2$

Critical value at 2 degrees of freedom whose $\mathrm{P}$ value is 0.05 was 2.920

The calculated value is less than the critical value hence we reject the null hypothesis and accept the alternative (Table 8). Therefore, implementation of regulations has an effect on the fish stock. This has been evident from the study since the fish stock decreased due to the ineffective implementation of regulations.

\subsection{Fish stocks}

\subsubsection{Trend of fish catch}

Fifty percent of the respondents reported that fish catch had in the recent times decreased while 30\% said that it was stagnant. The remaining $20 \%$ stated that there was an increase on the fish catch from the lake as observed in Fig. 13. The decrease in fish catch could be attributed to the increased fishing efforts.

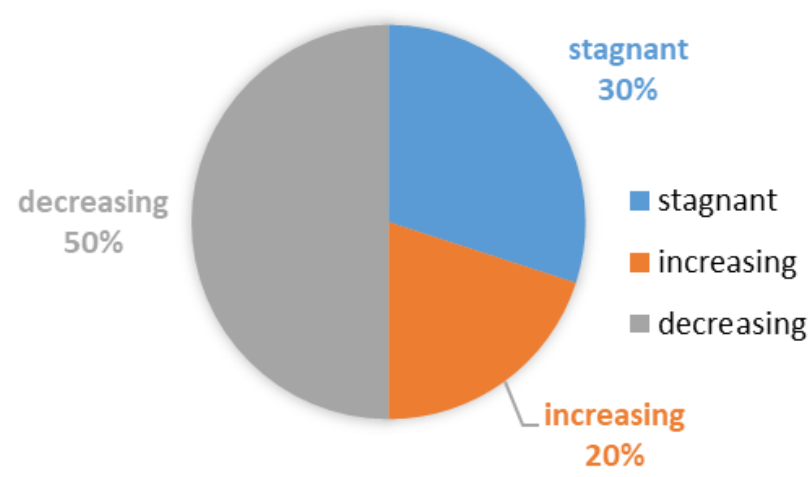

Fig. 13. Trend of fish catches

The main fish species landed on the Island was Nile perch, making it the principal target species. Most of the fishermen on the Island handled (landing and trading) Nile perch as it earns a higher income compared to other fish species- tilapia and mud fish. This can be credited to the export market it enjoys. According to the BMU chairman, fish processors in Kisumu and Nairobi have assigned their buying agents on the Island who have refrigerated trucks along the mainland beaches, to purchase the commodity.

\subsubsection{Trend of fishermen}

As reported by $92 \%$ of the respondents, the number of fishermen in Migingo Island has increased. $6 \%$ of the respondents stated that the numbers had been the same while $2 \%$ said they were decreasing as seen in Fig. 14 .

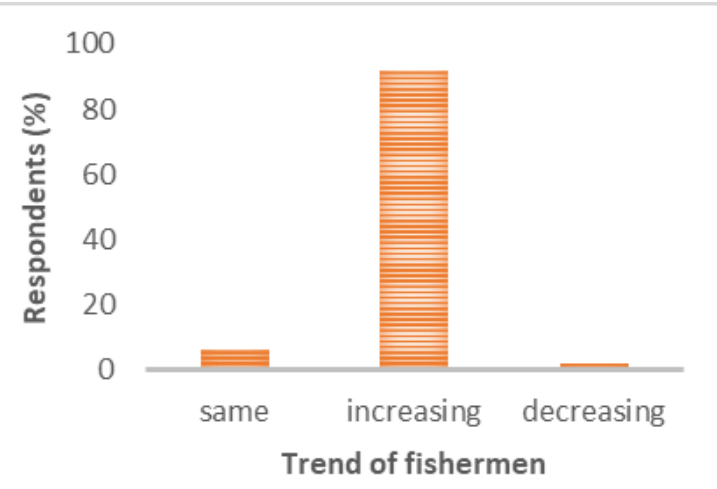

Fig. 14. Trend of fishermen in Migingo Island

According to the BMU chairman over 200 boats on an annual basis operate in the waters around the island and land their fish. The rise in the number of fishermen can be traced 
to the landing site in Migingo Island where they can sell the fish to be stored in coolers hence avoiding post-harvest loss.

\section{Conclusion}

The research revealed that the structure of the Migingo BMU was wanting as it comprised of a committee and lacked an assembly. This rendered the management of the BMU to being inefficient and ineffective due to its weak structure. The committee as the remaining and functional arm of the BMU was dominated by boat owners hence marginalizing the fishermen, traders and processors who mostly are women, from the decision-making process. The Migingo BMU only performs three out of seven functions satisfactorily. These include: collection of revenues, confiscation of illegal gears and arrest of offenders. The remaining duties- conducting meetings, patrol of the lake, formulation of bylaws and keeping of inventories were performed unsatisfactorily. The high rate of performance in the three named functions can be linked to the incentive that comes along with it, the monetary benefits it begets the BMU officials. The poor performance in the four functions can be linked to the frequency at which they were carried out. In most cases this coincided with randomly or never done. As observed BMU officials are keen to explore avenues that have upfront and direct benefits to those whose benefits are long standing, improves the community's livelihood and sustainably exploits the fisheries resource.

It was noted that the community's participation aided in the management of BMUs by providing the needed manpower in instances of identifying offenders. However their opinion during decision making processes was rarely sought after and they could hardly access information concerning the BMU. In the event they did, it was mainly through word of mouth. The study reported that operations of the BMU in terms of undertaking functions had elicited moderate compliance to the regulations. The confiscation of illegal gears and arrest of offenders had instilled fear on the fishers not to engage in unsustainable fishing practices while lack of a patrol system made room for illegal fishing activities to continue being undetected.

Implementation of regulations was said to be hindered by: inadequate resources (funds and equipment); lack of support from the government; inadequate capacity and; inadequate knowledge to operate its functions. In effective implementation of regulations had caused a decrease in the fish catch from the lake while the number of fishermen was on the rise. In order for effective management of the Migingo BMU to be attained, its assembly should be formed and the composition of the BMU should include and represent stakeholders equally. With the complete structure of the BMU in place, they should be supported by the government through capacity building to equip them with skills and allocation of funds and equipment to perform their duties efficiently.

\section{Recommendations}

The following recommendations arose from the study that was conducted.

a) Training of the BMU members on its management roles in relation to structure, functions and legal power to improve its impact on sustainable fisheries activities. A representative from the fisheries department representing the County and National Governments should train the members and interested stakeholders on the structure and functions so as to ensure an efficient management of the fisheries through the BMU.

b) Capacity building of the community to inform them of the operations of the Migingo BMU and its importance on the fisheries management and consequently on the socio-economic development of the Island. The Migingo BMU alongside the County Government should take this initiative of creating awareness by holding meetings/ barazas on a regular basis where every member of the community is invited and informed of the importance of the resource and legal structures in place to manage and govern the fisheries.

c) Support from the County and National Governments in terms of funds and equipment that will enable BMUs to effectively carry out their duties. This would improve the operations of the BMUs and foster a stronger collaboration between the levels of management. As a result there will be increased information sharing that may lead to better planning of the fishery resources for sustainability.

d) Equal Inclusion of all stakeholders in the co management of the fisheries resource. An empowered community that is well informed of the regulations governing the resource will ensure that all the stakeholders are well represented and included in the BMU committee and assembly.

e) Use of technology in the management of BMUs by create an app that aids in record keeping for the BMU officials hence enabling them to plan for future endeavors. Use of drones to patrol the fishing grounds. This will reduce the cost and it is highly reliable. Innovations should be undertaken by the fishing community, research and academic institutions. The BMU should gather its resources and invest in these technologies to make management more effective.

f) Improvement of physical infrastructure and social amenities within the Island such as fish landing stations, dispensaries and sanitation facilities. Community based organizations should be formed and take up the above mentioned roles. This would not only improve the infrastructure in the region but also create an alternative source of employment hence reducing the pressure on the fishery resource.

g) Further research should be done on the fishing communities, the fisheries resource and the Lake Victoria ecosystem 
in order to understand how successful governance and management can be accomplished.

\section{Acknowledgements}

This work was in part supported by the University of Nairobi's Education for Sustainable Development in Africa- Sustainable Urban Development (ESDA-SUD) - a component of the ESDA program, which is a collaboration of eight African Universities with the support of the African Development Bank.

\section{References}

Abila R. O., Yongo E. O. \& Lwenya C. (2009). Socio-economic baseline survey of the fishing communities of Lake Victoria, Kenya. KMFRI Technical Report No. 1/ 2009, Kisumu, Kenya, 24-36. Google scholar

Abila R. O., Lwenya C., Geheb K. \& Crean K. (2000). An assessment of co-management potentials in the Lake Victoria fisheries of Kenya. In: The Co-Management Survey: Co-Management Perspectives for Lake Victoria Fisheries (eds K. Geheb \& K. Crean), LVFRP/TECH/00/11 LVFRP Technical Document NO. 11, Jinja, Uganda 1-10. Google scholar

Abila Richard (2014). Socio-economic Sustainability and Viability of Beach Management Units in Lake Victoria.

Food and Agriculture Organization (FAO) (2016). Fisheries and Resources Monitoring System (FIRMS) - Concepts \& Definitions. FIRMS Techincal Working Group Meeting. 5th session.

Japp D., (2012). Kenya Fisheries governance. Implementation of a Regional Fisheries Strategy for the Eastern and Southern Africa and Indian Ocean Region. REPORT/RAPPORT: SF/2012/9, 12-13

Lawrence T. \& Watkins C. (2011). It takes more than a village: The challenges of co-management in Uganda's fishery and forestry sectors. Int. J. Sust. Dev. World 19(2), 1-11. http://dx.doi.org/10.1080/13504509.2011.606510
Lwenya C. A., Lwenya K., Abila R. \& Omwega, R. (2018). Gender participation in fisheries management of Lake Victoria, Kenya. Ocean Docs Journal. Vol 2 p.266-272. Google scholar

Luomba J., and Kristofersson D. M.,(2013) Role of Beach Management Units in Implementing Fisheries Policy: A case study of two BMUs in Lake Victoria Tanzania. United Nations University, Fisheries Training Programme, 6-8. Google scholar

Muigua K., (2016). Nurturing our Environment for Sustainable Development. Glenwood Publishers Limited, vol.2, 87-91. Google scholar

Muigua K., Wamukoya D., and Kariuki F., (2015). Natural Resources and Environmental Justice in Kenya. Glenwood Publishers Limited vol.1, 65-69. Google scholar

Ngwenya B. \& Mosepele K. (2012). A case of Gender Equity in governance in the Okvango deltafisheries in Botswana. Natural Resources Forum 36, pp. 109-122. http://dx.doi.org/10.1111/j.1477-8947.2012.001450.x

Nunan F. (2010). Governance and Fisheries Co-management on Lake Victoria: Challenges to the Adaptive Governance Approach. Mast. Volume 10, 103-125. Google scholar

Njiru M., Kazungu J., Ngugi C. C., Gichuki J. \& Muhoozi L. (2008) An overview of the current status of Lake Victoria fishery: Opportunities, challenges and management strategies. Lakes Reserv. Res. Manage. 13, 1-12. https:// doi.org/10.1111/j.1440-1770.2007.00358.x

Ogwang Vincent (2005). Guidelines for beach management units (BMUs) on Lake Victoria. LVFO-EAC IRC Repository, East African Community's institutional repository. Google scholar

Pomeroy, S. R, Joshua E. C \& Nielsen, J. R. (2011). Conditions for successful. Co management: Lessons Learned in Asia, Africa, the Pacific and Wider Caribbean. In R. S. Andrew, Small Scale Fisheries Management-Frameworks and Approaches for the Developing World. vol 2, pp. 115-131. Google scholar

Van der Knaap M., Ntiba M. J. \& Cowx I. G. (2002). Key elements of fisheries management on Lake Victoria. Aquatic Ecosystem Health Management Journal. 5, 245-254. https://doi.org/10.1080/14634980290031947 